\title{
Endovascular versus surgical treatment of cranial dural arteriovenous fistulas: a single-center 8-year experience
}

\author{
Wilhelm Sorteberg ${ }^{1} \cdot$ Angelika Sorteberg $^{1,2} \cdot$ Eva Astrid Jacobsen $^{3} \cdot$ Pål Rønning ${ }^{1} \cdot$ Terje Nome $^{3}$. \\ Per Kristian Eide ${ }^{1,2}$ (-)
}

Received: 23 December 2020 / Accepted: 5 April 2021 / Published online: 6 September 2021

(c) The Author(s) 2021

\begin{abstract}
Background Cranial dural arteriovenous fistulas (dAVFs) are rare lesions managed mainly with endovascular treatment (EVT) and/or surgery. We hypothesize that there may be subtypes of dAVFs responding better to a specific treatment modality in terms of successful obliteration and cessation of symptoms and/or risks.

Methods All dAVFs treated during 2011-2018 at our hospital were analyzed retrospectively. Presenting symptoms, radiological variables, treatment modality, complications, and residual symptoms were related to dAVF type using the original Djindjian classification.

Results We treated 112 dAVFs in 107 patients $(71,66 \%$ males). They presented with hemorrhage $(n=23 ; 21 \%)$, nonhemorrhagic symptoms $(n=75 ; 70 \%)$, or were discovered incidentally $(n=9 ; 8 \%)$. There were $25(22 \%)$ type I, $29(26 \%)$ type II, 26 (23\%) type III, and $32(29 \%)$ type IV fistulas. EVT was the primary treatment modality in $72 / 112(64 \%)$ dAVFs whereas $40 / 112$ (36\%) underwent primary surgery with angiographic obliteration rates of $60 \%$ and $90 \%$, respectively. Using a secondary treatment modality in $23 \mathrm{dAVFs}$, we obtained a final obliteration rate of 93\%, including all type III/IV and 26/27 (96\%) type II dAVFs. Except for headache, residual symptoms were rare and minor. Permanent neurological complications consisted of five cranial nerve deficits.

Conclusions We recommend EVT as first treatment modality in types I, II, and in non-hemorrhagic type III/IV dAVFs. We recommend surgery as first treatment choice in acute hemorrhagic dAVFs and as secondary choice in type III/IV dAVFs not successfully occluded by EVT. Combining the two modalities provides obliteration in $9 / 10 \mathrm{dAVF}$ cases at a low procedural risk.
\end{abstract}

Keywords Dural arteriovenous fistula $\cdot$ Intracranial hemorrhage $\cdot$ Cerebral venous aneurysm $\cdot$ Treatment $\cdot$ Outcome

This article is part of the Topical Collection on Vascular Neurosurgery - Other

Per Kristian Eide

p.k.eide@medisin.uio.no

1 Department of Neurosurgery, Oslo University Hospital Rikshospitalet, P.B. 0454 Nydalen, 0424 Oslo, Norway

2 Institute of Clinical Medicine, Faculty of Medicine, University of Oslo, Oslo, Norway

3 Department of Radiology and Nuclear Medicine, Oslo University Hospital - Rikshospitalet, Oslo, Norway

\section{Introduction}

A cranial dural arteriovenous fistula (dAVFs) is a rare type of neurovascular lesion with a detection rate of $0.16 / 100,000$ adult years [1]. They may be discovered incidentally, but depending on their location and venous drainage, they may cause pulsatile tinnitus, headache, ocular and neurological symptoms, or intracranial hemorrhage $[8,12,19,20,22,23$, $26,29]$. Once discovered, dAVFs are delineated using cerebral six-vessel digital subtraction angiography (DSA) and categorized according to their drainage into dural sinuses and leptomeningeal veins. The most common classifications are the Djindjian, Borden, Cognard, and the Directness, Exclusivity, and Strain (DES) [3-5, 7, 10, 13].

The choice of treatment is based on presenting symptoms and the dAVF angioarchitecture. Although endovascular 
treatment (EVT) has become the primary treatment modality of most cranial dAVFs [2, 19, 20, 26, 29], surgery is used in various settings [5, 20, 31, 32]. The advantage of each treatment modality in relation to the type of dAVF and clinical setting is, however, not fully delineated. By presenting our experience of dAVF treatment with both treatment modalities, we want to expand the existing knowledge by systemising their use in accordance with dAVF type and clinical setting. The hypothesis is that there may be subtypes of dAVF responding better to a specific treatment modality in terms of successful obliteration and cessation of symptoms and/or risks. To this end, we retrospectively analyzed the clinical, radiological, treatment, and complication data of all patients with cranial dAVFs treated with EVT and/or surgery at our hospital during the 8-year period 2011-2018.

\section{Material and methods}

\section{Infrastructure}

Oslo University Hospital has been designated to be the national referral center for EVT in neurovascular malformations by the Norwegian Health Authorities. The vast majority of cranial dAVFs in Norway (population 5.3 million 2020; www.ssb.no) are therefore treated at our institution.

Our goals for treatment are prevention of intracranial hemorrhage/rebleed, reversal of neurological/ocular symptoms, and palliation of intolerable symptoms due to the dAVF blood flow.

Elective cases are evaluated in weekly meetings by our neurovascular team consisting of neuro-interventionists from the Department of Radiology and vascular neurosurgeons from the Department of Neurosurgery. For each patient, detailed medical history and the results of clinical neurological examination are considered together with the radiological findings. Emergencies are managed by the vascular neurosurgeon and neuro-interventionist on call.

\section{Patients and data collection}

All adult patients with cranial dAVFs in whom endovascular/surgical treatment was initiated and completed at our hospital from January 2011 through December 2018 were included in this retrospective study. Excluded were eight patients that had treatment of Barrow type A high-flow carotid-cavernous fistulas [6], two patients that received part of their treatment at other hospitals, and one patient in whom treatment was not completed until 2019.

Data were retrieved from medical records, PACS (Sectra ${ }^{\circledR}$ AB, Linköping, Sweden), and surgical protocols. We registered demographic data, clinical presentation, dAVF characteristics (lesion location and venous drainage), and treatment modality. Treatment was evaluated according to residual symptoms, angiographic dAVF obliteration, and procedural complications.

The study was approved as a quality control project by the institutional data protection officer (number 2012/14909) and exempt from informed consent.

\section{dAVF classification}

We categorized the dAVFs according to the original classification system that Djindjian et al. introduced in 1977 [13], which is the system Borden et al. based their classification of 1995 on [7]. The subtypes are presented in Table 1, also including the Cognard classification [10]. While types I and II correspond in the Djindjian and Borden systems, Borden type III dAVF draining into leptomeningeal vein(s) was in the Djindjian classification differentiated into types III and IV, depending on the absence or presence of aneurysmatic/ ectatic segment(s) on the leptomeningeal draining vein(s)

Table 1 Current classifications of dAVFs

\begin{tabular}{|c|c|c|c|}
\hline Type & Djindjian [13] & Borden [7] & Cognard [10] \\
\hline I & $\begin{array}{l}\text { Normal antegrade drainage into dural sinus } \\
\text { or meningeal veins only }\end{array}$ & $\begin{array}{l}\text { Normal antegrade drainage into dural sinus } \\
\text { or meningeal veins only }\end{array}$ & $\begin{array}{l}\text { Normal antegrade drainage into dural sinus or } \\
\text { meningeal veins only }\end{array}$ \\
\hline II & $\begin{array}{l}\text { Drainage both into dural sinus and retro- } \\
\text { grade into leptomeningeal vein(s) }\end{array}$ & $\begin{array}{l}\text { Drainage both into dural sinus and retro- } \\
\text { grade into leptomeningeal vein(s) }\end{array}$ & $\begin{array}{l}\text { a) Retrograde drainage into dural sinus(es) } \\
\text { b) Retrograde drainage into cortical vein(s) } \\
a+b) \text { Retrograde drainage into dural sinus(es) } \\
\text { and cortical vein(s) }\end{array}$ \\
\hline III & $\begin{array}{l}\text { Exclusive retrograde drainage into leptome- } \\
\text { ningeal vein }(\mathrm{s}) \text { without any aneurysmatic } \\
\text { or ectatic venous segments }\end{array}$ & $\begin{array}{l}\text { Exclusive retrograde drainage into leptome- } \\
\text { ningeal vein(s) } \\
\text { No differentiation whether aneurysmatic or } \\
\text { ectatic venous segments are present or not }\end{array}$ & $\begin{array}{l}\text { Exclusive retrograde drainage into leptome- } \\
\text { ningeal vein(s) without venous ectasia }\end{array}$ \\
\hline IV & $\begin{array}{l}\text { Exclusive retrograde drainage into lep- } \\
\text { tomeningeal vein(s) with aneurysmatic or } \\
\text { ectatic venous segments }\end{array}$ & & $\begin{array}{l}\text { Exclusive retrograde into leptomeningeal } \\
\text { vein(s) with venous ectasia }>5 \mathrm{~mm} \text { and } \times 3 \\
\text { larger than diameter of draining vein }\end{array}$ \\
\hline V & & & Drainage to spinal perimedullary veins \\
\hline
\end{tabular}


(Table 1). An example of Djindjian type III (corresponding to Borden type 3 ) is shown in Fig. 1, and an example of Djindjian type IV (corresponding to Borden type 3 ) is shown in Fig. 2.

Hemorrhagic cases were also evaluated with regard to the presence of a congestive pseudophlebitic venous appearance [3] (see Fig. 3).

\section{Institutional management principles}

In general, new patients undergo a (new) preoperative sixvessel DSA at our institution to delineate the dAVF prior to treatment. If the clinical state in acute cases requires emergency hematoma evacuation, this is performed immediately after arrival, based on cerebral CT/CTA without a preoperative DSA.

Embolization of a dAVF aims to occlude the fistula by access through arterial feeders and/or a draining vein by occluding the foot of the draining vein(s) [19]. Selection of catheters and embolic materials depends on access route(s) and the dAVF angioarchitecture. Usually, a dimethyl sulfoxide (DMSO)-compatible micro catheter is positioned close to the fistulous site and DMSO-compatible embolic

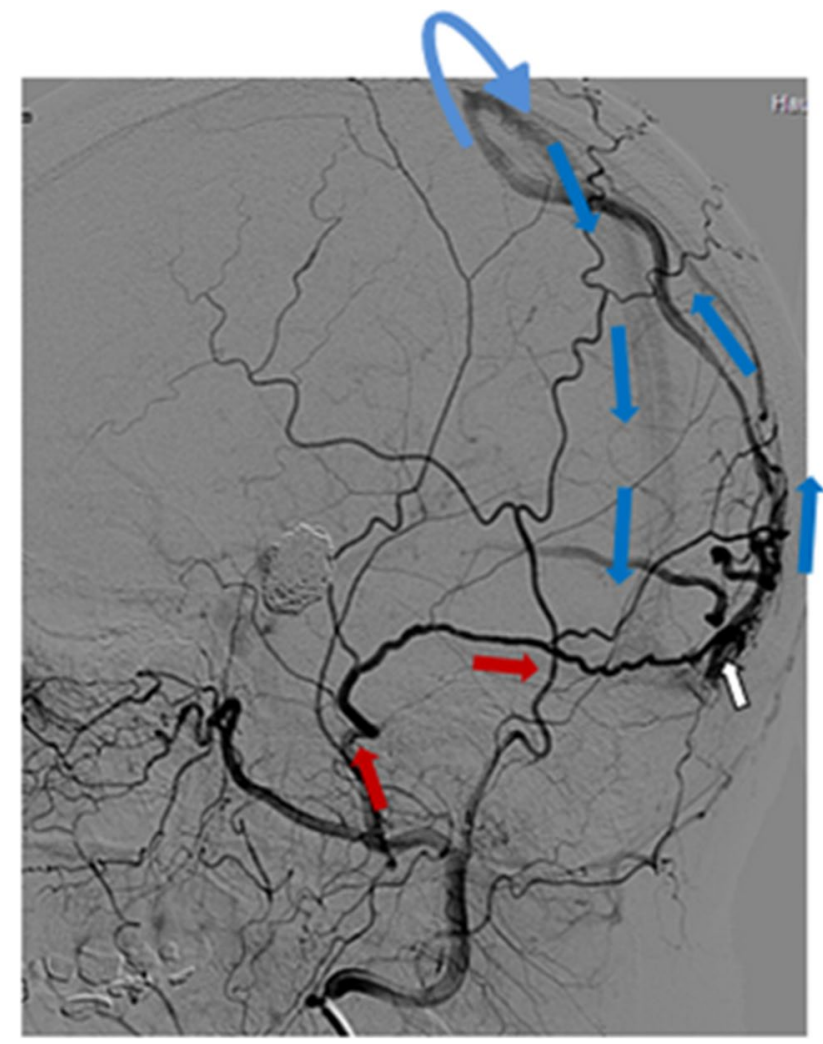

Fig. 1 Oblique projection of a dAVF (white arrow) with leptomeningeal drainage of Djindjian type III. Cerebral angiography with contrast in the occipital artery supplying the fistula (red arrows) and retrograde venous drainage to the superior sagittal sinus (blue arrows)

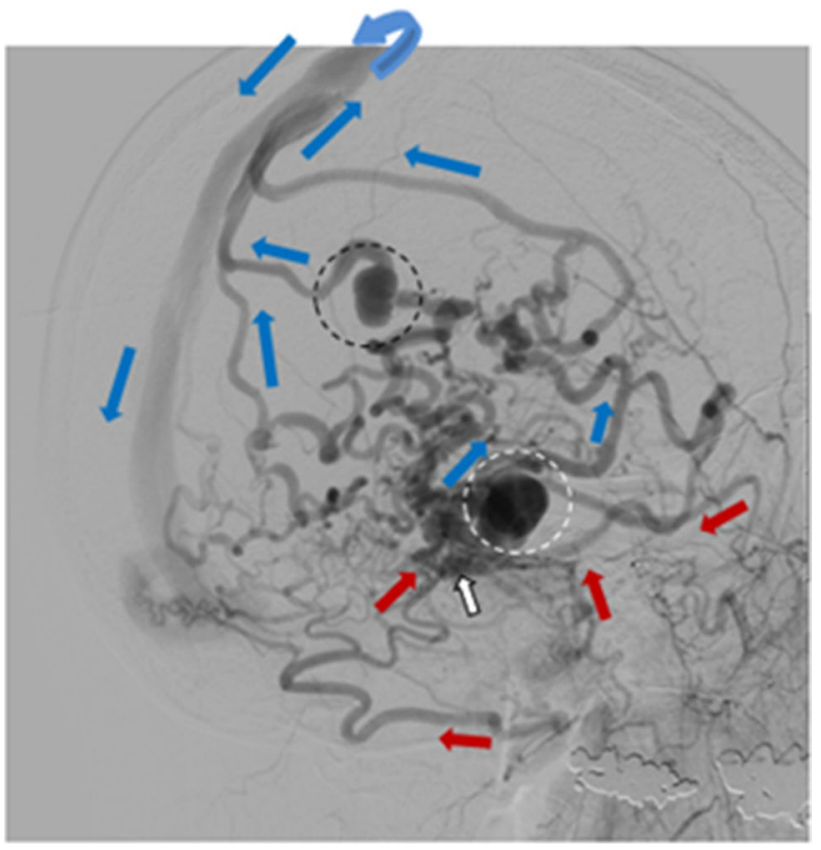

Fig. 2 Oblique projection of a dAVF (white arrow) with leptomeningeal drainage of Djindjian type IV. Cerebral angiography with contrast in the occipital artery (left two red arrows) and middle meningeal artery (right two red arrows) supplying the fistula and retrograde venous drainage to the superior sagittal sinus (blue arrows) with venous ectasias/aneurysms (circles) on the draining veins

material is injected with or without balloon protection of the sinus, and with or without additional occlusion of draining venous ectasias with coils. We usually prefer the transvenous route for cavernous sinus dAVFs due to the combination of a higher clinical and anatomic cure and a lower incidence of complications compared to the transarterial route [29].

The preferred surgical treatment of type III/IV dAVFs is disconnection of the leptomeningeal vein(s) where it (they) emerge(s) from the fistula, thereby ensuring all routes of venous outflow are obliterated $[11,15]$. In type II dAVFs, one may perform dAVF excision with resection of the sinus and not just venous disconnection. In patients with distal tortuous arterial feeders to dAVFs that cannot be reached adequately through transarterial endovascular routes, one may in rare cases perform surgical palliative distal extracranial feeding artery disconnection.

Patients that underwent elective embolization were routinely discharged to home the day after treatment. Most patients with some residual dAVF flow at the end of the EVT underwent control DSA at 3 months. After elective surgery, patients routinely underwent cerebral CT/CTA on the first postoperative day and postoperative DSA during the primary stay or at a follow-up visit. Our management of patients with acute intracranial hemorrhage from cranial dAVFs has been described recently [31]. 
Fig. 3 Cerebral angiography (anterior-posterior and lateral projections) showing a dAVF (white arrow) with pseudophlebitic venous appearance (circles) of leptomeningeal drainage (blue arrows). Arterial supply from the occipital artery (red arrows)
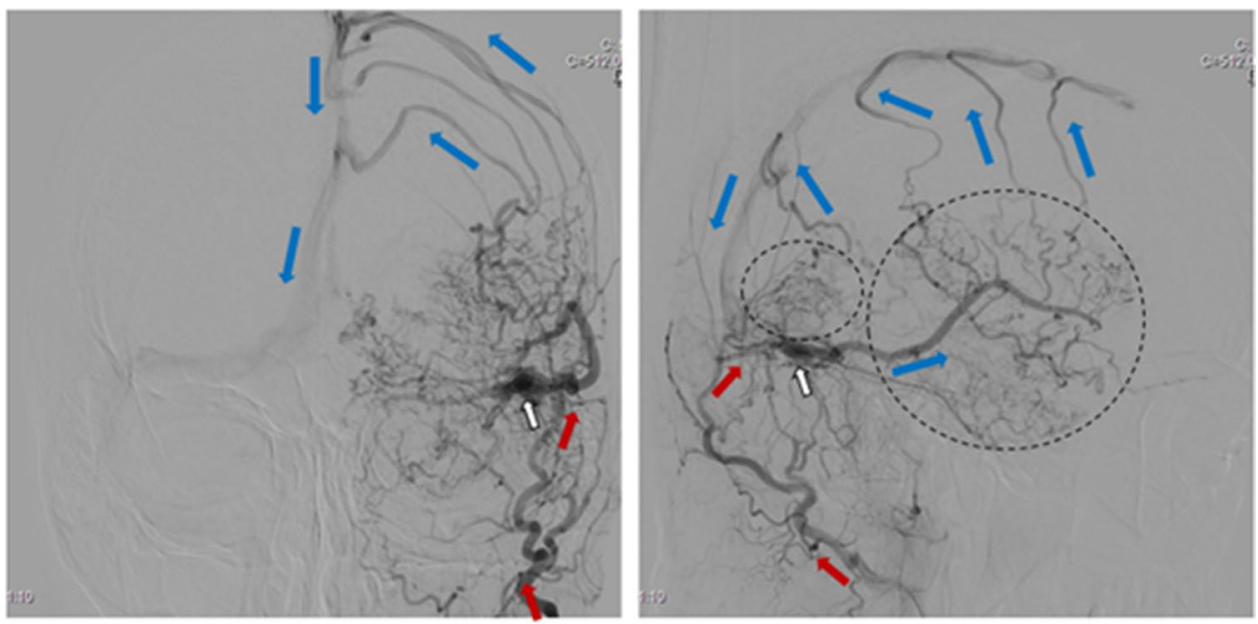

\section{Statistics}

Statistical analysis was performed using SPSS version 25 (IBM Corporation, Armonk, NY, USA). Not normal distributed continuous variables are presented with median and range Categorical variables are presented as frequencies or percentages, and the Chi square test was used to compare differences between independent groups, whereas one-sample binomial tests were used to assess differences in frequencies within one category. Two tailed $p$-values of less than 5\% were considered statistically significant.

\section{Results}

\section{Patients}

Table 2 shows demographic information, clinical presentation, dAVF type, treatment modality, and management results. The median time from start of symptoms/incidental finding to treatment was 7 months (range 0 days -48 months).

EVT was predominantly used as primary treatment in type I and type II dAVFs, whereas there was no predominance in type III and a trend to surgery in type IV dAVFs. Surgery was chosen as primary treatment in most hemorrhagic cases.

Predisposing factors for dAVF were unknown in 90/107 (84\%) patients, whereas seven (7\%) had a history of facial/ head injury, five (5\%) of dural sinus thrombosis, three (3\%) of cranial neurosurgery, and two (2\%) of central nervous system infection.

\section{Clinical presentation versus dAVF type}

All hemorrhagic dAVFs drained into leptomeningeal veins only (type III $(n=2)$ and types IV $(n=21))$, whereas $2 / 9$ incidentally discovered fistulas drained also into a venous sinus (type II ( $n=2)$, type III $(n=3)$, and type IV $(n=4))$. Type I dAVFs were merely found in non-hemorrhagic symptomatic patients; these 75 patients harbored 80 fistulas: type I $(n=25)$, type II $(n=27)$, type III $(n=21)$, and type IV $(n=7)$.

\section{dAVF characteristics versus treatment}

Table 3 presents dAVF type and location versus primary treatment modality of all 112 fistulas, including gender representation of the various dAVFs.

Primary surgery led to a higher frequency of dAVF occlusion than EVT ( 90 versus $60 \%, p=0.003$, Table 2 ). Whereas the residual $29 \mathrm{dAVFs}$ after primary EVT were of all types (type I $(n=6)$, type II $(n=13)$, type III $(n=5)$, type IV $(n=5))$, the four dAVF residuals after primary surgery were only of type I $(n=1)$ and type II $(n=3)$. Twenty-three of the 33 residual dAVFs had secondary treatment, 20 with secondary surgery and three with secondary EVT (see Table 2). The 107 patients hence underwent totally 157 treatment procedures, 96 endovascular and 61 surgical. Whereas $75(70 \%)$ patients had just one procedure, 23 (21\%) underwent two (three patients had treatment of two separate fistulas) and nine had 3-8 procedures. The patient with eight procedures underwent treatment of three separate type II dAVFs.

The endovascular procedures included 73 transarterial-, 18 transvenous-, and five combined transarterial/transvenous procedures. The most frequent arteries used were the middle meningeal artery $(n=51)$, the occipital artery $(n=20)$, and the ascending pharyngeal artery $(n=6)$. Transarterially, liquid embolic materials (Squid® $n=40$, Onyx ${ }^{\circledR} n=25$, PHIL ${ }^{\circledR} n=5$, N-butyl cyanacrylate $n=5$ ) and endovascular coils $(n=8)$ were injected/inserted. The transvenous approaches were through the transversesigmoid sinus $(n=13)$, the inferior petrous sinus $(n=5)$, and the ophthalmic vein $(n=5)$; coils were deposited in all procedures. Nine of the transvenous procedures were 
Table 2 Patients, presentation, dAVF type, treatment, and results versus treatment modality in 107 patients with 112 dAVFs

\begin{tabular}{|c|c|c|c|c|}
\hline & \multirow[b]{2}{*}{ Total } & \multicolumn{2}{|l|}{ Treatment modality } & \multirow[t]{2}{*}{$P$-value } \\
\hline & & Primary EVT & Primary surgery & \\
\hline \multicolumn{5}{|l|}{ Demographic information } \\
\hline Number & 107 & 67 & 40 & 0.012 \\
\hline Gender male $\% /$ female $\%$ & $66 \% / 33 \%$ & $52 \% / 48 \%$ & $90 \% / 10 \%$ & $<0.001$ \\
\hline Age (years) & $56.1 \pm 13.1$ & $54.4 \pm 14.3$ & $59.1 \pm 10.1$ & 0.072 \\
\hline \multicolumn{5}{|l|}{ Clinical presentation } \\
\hline Hemorrhage & 23 & $6(26 \%)$ & $17(74 \%)$ & 0.035 \\
\hline Non-hemorrhagic symptoms & 75 & $56(75 \%)$ & $19(25 \%)$ & $<0.001$ \\
\hline $\begin{array}{l}\text { Incidental } \\
\text { dAVFs }\end{array}$ & \multicolumn{3}{|c|}{ dAVFs } & 1.000 \\
\hline Type I & 25 & $24(96 \%)$ & $1(4 \%)$ & $<0.001$ \\
\hline Type II & 29 & $25(86 \%)$ & $4(14 \%)$ & $<0.001$ \\
\hline Type III & 26 & $13(50 \%)$ & $13(50 \%)$ & 1.000 \\
\hline Type IV & 32 & $10(31 \%)$ & $22(69 \%)$ & 0.052 \\
\hline \multicolumn{5}{|l|}{ Treatment modality } \\
\hline Primary treatment & 112 & $\begin{array}{l}72(64 \%) \\
\text { (primary EVT) }\end{array}$ & $\begin{array}{l}40(36 \%) \\
\text { (primary surgery) }\end{array}$ & 0.003 \\
\hline Secondary treatment & 23 & $\begin{array}{l}20(87 \%) \\
\text { (secondary surgery) }\end{array}$ & $\begin{array}{l}3(13 \%) \\
\text { (secondary EVT) }\end{array}$ & $<0.001$ \\
\hline \multicolumn{5}{|l|}{ Management results } \\
\hline Primary treatment occlusion & $79 / 112(71 \%)$ & $43 / 72(60 \%)$ & $36 / 40(90 \%)$ & 0.001 \\
\hline Secondary treatment occlusion & $19 / 23(83 \%)$ & $16 / 20(75 \%)$ & $3 / 3(100 \%)$ & 0.394 \\
\hline $\begin{array}{l}\text { Late spontaneous occlusion after } \\
\text { primary/secondary treatment }\end{array}$ & 6 & 5 & 1 & 1.000 \\
\hline Final occlusion & $104 / 112(93 \%)$ & $64 / 72(89 \%)$ & $40 / 40(100 \%)$ & 0.029 \\
\hline
\end{tabular}

treatment of cavernous sinus dAVFs and included endovascular reopening of a thrombosed inferior petrous sinus $(n=3)$ and surgical exposure for direct puncture of the superior ophthalmic vein $(n=3)$.

The surgical procedures included dAVF leptomeningeal draining vein disconnection $(n=47)$, dAVF excision with resection of the sinus $(n=6)$, dAVF excision only $(n=2)$, and distal extracranial feeding artery disconnection $(n=6)$.

Including primary and secondary treatment as well as the six dAVFs that occluded spontaneously late (>3 months) after treatment, we obtained a final angiographic obliteration in 104/112 (93\%) dAVFs (see Table 2), including 84/85 (99\%) dAVFs with leptomeningeal venous drainage (types II/III/IV) that had follow-up angiography - the last dAVF (type II) was converted into a type I fistula with minor symptoms.

Among the six patients with residual dAVF flow after primary EVT but with no angiographic follow-up, two out of four type I dAVF patients became asymptomatic whereas the other two had minor residual symptoms (pulsatile tinnitus). Both patients with type II dAVFs became asymptomatic within weeks after the EVT.

\section{Presenting and residual symptoms in non-hemorrhagic patients}

Presenting and residual symptoms of the 75 non-hemorrhagic patients are listed in Table 4 . Headache was a common presenting symptom of dAVFs in all locations whereas pulsatile tinnitus and ocular symptoms were mostly linked to dAVFs located close to the middle ear and the cavernous sinus: in 39/45 and 12/14 cases, respectively. At a median of 10 months (range 2-106 months) after treatment, the symptom intensity was reduced in the $2 / 45(4 \%)$ patients that still had some pulsatile tinnitus, the $1 / 14$ (7\%) patient with some residual ocular symptoms, and in the 4/12 (33\%) patients that had some residual neurological symptoms. Residual headache was significantly more common than residuals of other symptoms ( $p<0.001$, Table 4$)$. In the 18 patients with residual headache, intensity had decreased in nine, was unaltered in eight, and increased in one patient as compared to pre-treatment level. Residual headache was present in $6 / 12(50 \%)$ of those that presented with headache only and in 12/30 (40\%) of those that also had other presenting symptoms. 
Table 3 dAVF characteristics (type and location) versus primary treatment modality in 107 patients with 112 dAVFs

\begin{tabular}{|c|c|c|c|c|c|c|c|c|c|c|}
\hline \multirow{2}{*}{$\begin{array}{l}\text { dAVF } \\
\text { Male } n(\%)\end{array}$} & \multicolumn{2}{|c|}{ Overall } & \multicolumn{2}{|c|}{ Type I } & \multicolumn{2}{|c|}{ Type II } & \multicolumn{2}{|c|}{ Type III } & \multicolumn{2}{|c|}{ Type IV } \\
\hline & \multicolumn{2}{|c|}{$75(63 \%)$} & \multicolumn{2}{|c|}{$13(52 \%)$} & \multicolumn{2}{|c|}{$21(72 \%)$} & \multicolumn{2}{|c|}{$17(65 \%)$} & \multicolumn{2}{|c|}{$24(75 \%)$} \\
\hline Type of primary treatment & EVT & SUR & EVT & SUR & EVT & SUR & EVT & SUR & EVT & SUR \\
\hline Primary treatment $n$ & 72 & 40 & 24 & 1 & 25 & 4 & 13 & 13 & 10 & 22 \\
\hline Primary treatment $\%$ & $64 \%$ & $36 \%$ & $96 \%$ & $4 \%$ & $86 \%$ & $16 \%$ & $50 \%$ & $50 \%$ & $31 \%$ & $69 \%$ \\
\hline \multicolumn{11}{|l|}{ Locations } \\
\hline Supra-tentorial (male $78 \%$ ) & 13 & 12 & - & - & 3 & - & 6 & 5 & 4 & 7 \\
\hline Superior sagittal sinus & 10 & 6 & - & - & 3 & - & 4 & 1 & 3 & 5 \\
\hline Cribriform plate & - & 4 & - & - & - & - & - & 2 & - & 2 \\
\hline Convexity & 2 & 2 & - & - & - & - & 1 & 2 & 1 & - \\
\hline Sphenoidal & 1 & - & - & - & - & - & 1 & - & - & - \\
\hline Tentorial (male 79\%) & 4 & 15 & - & - & - & 1 & - & 5 & 4 & 9 \\
\hline Tentorial type 1 & 1 & 1 & - & - & - & 1 & - & - & 1 & - \\
\hline Tentorial type 2 & 2 & 7 & - & - & - & - & - & 4 & 2 & 3 \\
\hline Tentorial type 3 & - & 1 & - & - & - & - & - & - & - & 1 \\
\hline Tentorial type 4 & - & 1 & - & - & - & - & - & - & - & 1 \\
\hline Tentorial type 5 & 1 & 4 & - & - & - & - & - & 1 & 1 & 3 \\
\hline Tentorial type 6 & - & 1 & - & - & - & - & - & - & - & 1 \\
\hline Transverse-sigmoid-jugular (male 62\%) & 42 & 11 & 17 & 1 & 17 & 2 & 6 & 2 & 2 & 6 \\
\hline Transverse & 4 & 2 & - & 1 & 3 & 1 & 1 & - & - & - \\
\hline Transverse-sigmoid angle & 19 & 5 & 8 & - & 5 & - & 4 & 1 & 2 & 4 \\
\hline Sigmoid & 15 & 4 & 6 & - & 8 & 1 & 1 & 1 & - & 2 \\
\hline Jugular bulb & 4 & - & 3 & - & 1 & - & - & - & - & - \\
\hline Marginal sinus (male $0 \%$ ) & 1 & - & - & - & - & - & 1 & - & - & - \\
\hline Cavernous sinus (male 50\%) & 12 & 2 & 7 & - & 5 & 1 & - & 1 & - & - \\
\hline
\end{tabular}

Numbers and percentages $(\%)$ of females and males are listed for the different dAVF types. Male percentage (\%) is listed for the main dAVF locations.

$E V T$, endovascular treatment; $S U R$, surgery.

Table 4 Presenting and residual symptoms in 75 patients with non-hemorrhagic symptoms in relation to dAVF location

\begin{tabular}{|c|c|c|c|c|c|c|}
\hline & $n$ & Supratentorial & Tentorial & $\begin{array}{l}\text { Transverse- } \\
\text { sigmoid-jugular }\end{array}$ & Marginal sinus & Cavernous \\
\hline$n$ & & 12 & 8 & 40 & 1 & 14 \\
\hline \multicolumn{7}{|c|}{ Pulsatile tinnitus } \\
\hline Presenting & 45 & 5 & 5 & 31 & - & 4 \\
\hline Residual & 2 & - & - & 2 & - & - \\
\hline \multicolumn{7}{|l|}{ Ocular } \\
\hline Presenting & 14 & - & - & 2 & - & 12 \\
\hline Residual & 1 & - & - & - & - & 1 \\
\hline \multicolumn{7}{|c|}{ Neurological } \\
\hline Presenting & 12 & 1 & 1 & 6 & - & 4 \\
\hline Residual & 4 & 1 & 1 & 1 & - & 1 \\
\hline \multicolumn{7}{|l|}{ Headache } \\
\hline Presenting & 42 & 11 & 6 & 15 & 1 & 9 \\
\hline Residual & 18 & 5 & 1 & 7 & 1 & 4 \\
\hline
\end{tabular}

There was some residual dAVF flow in both patients with residual pulsatile tinnitus. Whereas all 14 patients with ocular symptoms had dAVF venous flow into orbital vein(s) prior to treatment, 13 became asymptomatic upon complete closure of their dAVF. In contrast, there was still some dAVF flow into the orbital vein in the patient with some residual 
ocular symptoms. There was no residual flow in the four patients with residual neurological symptoms or in the 18 patients with residual headache.

\section{Hemorrhagic patients}

The 23 hemorrhagic patients (17, 74\% males) presented with one out of two distinct separate symptoms: acute headache ( $n=19,83 \%)$ or acute neurological symptoms without headache $(n=4,17 \%)$. The hemorrhagic dAVFs were all type III $(2 / 23,9 \%)$ or type IV $(21 / 23,91 \%)$; moreover, the DSA of $5 / 23(22 \%)$ patients had a congestive pseudophlebitic venous appearance (see Fig. 3). There was a close relationship between the presenting symptom and the angiographic findings: In 17/19 (89\%) patients with acute headache, the DSA showed a venous aneurysm with a bleb linked to the hemorrhage whereas in $4 / 4(100 \%)$ patients presenting with acute neurological symptoms without headache, the DSAs had a congestive pseudophlebitic venous appearance. In contrast, this venous appearance was present in only $1 / 19(5 \%)$ patients presenting with acute headache.

Whereas 20/23 (87\%) patients were treated median $18 \mathrm{~h}$ (range $3 \mathrm{~h}-10$ days) after ictus, the other three were managed two, seven, and 8 months after the hemorrhage. Type IV dAVFs presented significantly more often with hemorrhage than type III $(21 / 32 ; 66$ versus $2 / 26 ; 8 \%, p<0.001)$.

There were seven (35\%) early rebleeds at median $7.5 \mathrm{~h}$ (range 3-96 h) among the 20 patients that were treated in the acute phase. Four of the twenty patients needed emergency haematoma evacuation. Among the other 16 patients, surgery $(n=12)$ was performed significantly faster after arrival than EVT ( $n=4$; median 13.0 versus $35.5 \mathrm{~h}, p<0.01$, Mann-Whitney test). Moreover, $2 / 4$ (50\%) of the primary EVT cases needed secondary surgery for complete dAVF closure.

Only $2 / 23$ (9\%) patients had symptoms prior to the hemorrhage: one suffered neck pain the last 6 months whereas the other developed change in personality, increasing dementia and gait disturbances over weeks and thereafter a decline in level of consciousness the last $48 \mathrm{~h}$ before ictus. Both patients became asymptomatic and recovered fully after treatment.

\section{Procedural complications}

There were $29(18 \%)$ procedural complications in 26 patients: 15 (16\%) from EVT and 14 (23\%) from surgery (Table 5). The five permanent neurological complications were all cranial nerve $(\mathrm{CN})$ deficits, two complete (CN VII and XII) and three partial (CN VI, VIII, and X). All three deficits after EVT (CN VI, X, and XII) occurred after transarterial embolization using Onyx ${ }^{\circledR}$. The approaches in the $\mathrm{CN} \mathrm{X}$ and XII cases were through the ascending pharyngeal
Table 5 Treatment complications to 96 endovascular and 61 surgical procedures in 107 patients with 112 dAVFs

\begin{tabular}{lll}
\hline Total & Endovascular & Surgical \\
\hline Number of procedures & 96 & 61 \\
Paresis & - & 1 (transient) \\
Cranial nerve dysfunction & 4 (1 transient) & 2 \\
Seizure & - & 2 \\
Postoperative hematoma & 3 (1 operated) & 2 (1 operated) \\
Aggravation of symptoms & 1 (transient) & 1 (transient) \\
Increase in dAVF type & 2 (2 transient) & - \\
Cranial muscle pain & 2 & 1 \\
Skin dysesthesia & 1 & 2 \\
Corneal erosion & - & 1 \\
Embolic material migration & 1 & \\
Arterial dissection & 1 & 1 \\
Aseptic bone flap necrosis & & 1 \\
Wound infection & & $\mathbf{1 4}(\mathbf{2 3 \%})$ \\
Number of complications & $\mathbf{1 5}$ (16\%) \\
\hline
\end{tabular}

artery (dAVFs of the hypoglossal canal/jugular bulb) and in the CN VI case through the middle meningeal-and occipital artery (dAVF along the superior sagittal sinus). In no case did the DSA images, also in retrospect, reveal unwanted catheter position during procedure or excessive reflux or untoward migration of Onyx. Also, follow-up CT and MRI in the patient with CN VI deficit showed no foreign body or ischemia in the brain/brainstem/orbits or along the CN VI origin/route. Both deficits after surgery (CN VII and VIII) occurred in settings with massive bleeding/extensive drilling of the petrous bone combined with dAVF excision and resection of the superior petrous sinus/sigmoid sinus.

\section{Discussion}

This study confirmed our hypothesis that our selection of treatment modality (EVT/surgery) depended heavily on the dAVF characteristics and clinical setting. Combining the two modalities gave a high (93\%) final angiographic obliteration rate, including all type III/IV fistulas. Outcome was favorable, with 52/77 (68\%) patients becoming asymptomatic and $5 \%$ permanent cranial nerve deficits.

\section{Classification of cranial dAVFs}

Presently, we used the original dAVF classification of Djindjian, which recently experienced a renaissance [17, 18], probably because it is simple, but still provides the most essential distinctions between dAVF subtypes. The more widely known classifications of Borden et al. and Cognard et al. are both based on the Djindjian system (see Table 1). 
One may notice that J-J Merland, the senior author of the work by Cognard et al. [10], was also a co-author of the work by Djindjian et al. [13].

The Djindjian classification was able to identify a dAVF subgroup more prone to hemorrhage (type IV) in our material, whereas the hemorrhagic cases would all have been Borden 3 cases without further distinction. A classification according to Cognard would have mirrored that of Djindjian as dAVF types III and IV are identical in the two systems. In contrast, whereas the Djindjan system categorized our 112 dAVFs into just four groups, the Cognard system would have produced seven groups. This further subdividing of groups would not have facilitated or altered our patient advices. Altered patient advice could possibly have occurred in some of the nine patients with incidental dAVFs that we treated if we had applied the concepts by Zipfel et al. [27, 34]. When considering treatment of a dAVF with leptomeningeal drainage, they include the natural history of the specific dAVF type and the case history of that particular patient. This is because a previous history of hemorrhage or non-hemorrhagic neurological symptom (NHNS) from the dAVF grossly increases the risk of future rebleed/NHNS, as compared to patients with benign symptoms/asymptomatic patients $[16,30,32]$. The present experience of $21 / 23(91 \%)$ of the hemorrhagic cases being asymptomatic prior to ictus, however, suggests elective treatment of asymptomatic type II-IV dAVFs unless patient frailty/medical contraindications exist.

The DES classification system added an extra dimension (congestive pseudophlebitic venous appearance) in our hemorrhagic patients that none of the other systems delineated. This identification and its link to clinical symptoms in hemorrhagic cases are discussed below.

\section{Patients and dAVF characteristics}

The age and male preponderance of our patients correspond with findings of others [2, 8, 18, 26, 29]. Our most frequent dAVF location, along the transverse-sigmoid sinus, also concurs with previous findings $[2,12,16,18,21-23]$. The presently high portion of type III/IV dAVFs (52\%) probably reflects the combination of a high fraction of hemorrhagic cases $(21 \%)$ and a low fraction (14\%) of patients with type I dAVF and intolerable symptoms.

\section{Endovascular versus surgical treatment}

In accordance with international trends, we used EVT as primary treatment in the majority of dAVFs, including $79 \%$ of non-hemorrhagic patients and $91 \%$ of types I/II. With treatment of some type I dAVFs being terminated prior to complete occlusion as intolerable symptoms had ceased, our primary EVT angiographic obliteration rate of $60 \%$ was lower than that obtained by Gross et al. (76\%) [18], Baltsavias and Valavanis (66\%) [2], Signorelli et al. (65\%) [29], and Guedin/Rodesch (64\%) [19], but higher than that of Kirsch et al. (54\%) [22] and Piippo (50\%) et al. [26]. Our results with primary surgery, perfect (100\%) obliteration of type III/IV dAVFs and very poor rates in types I/II, underline both the suitability of surgery in treatment of types III/IV and inadequacy of this modality in treating type I/II dAVFs unless the goal is to convert a type II into type I fistula [33] or merely symptomatic treatment (i.e., pulsatile tinnitus) of a type I dAVF. The present $88 \%$ obliteration rate of primary/ secondary treatment is similar to the results from combined treatment during the years 2000-2006 of Piippo et al. (81\%) [26], but higher than that of Signorelli et al. (27/39, 69\%) [29]. Also, the presently spontaneous occlusion of six partially treated dAVFs compares well with that of Gross et al. [17].

Due to its less invasive nature, EVT is a more attractive dAVF treatment modality than surgery. In situations of no procedure-related complications, EVT is very gentle with the brain and leaves no wound so that the patient can usually go home the day after elective treatment and be fit to return to work within days. In contrast, even after successful treatment, a surgically treated patient needs weeks to fully recover. From this, and also based on our dAVF obliteration rates, we recommend EVT as the primary treatment modality in all type I and type II dAVFs. Furthermore, we recommend that EVT should be tried as the first treatment option in non-hemorrhagic type III/IV dAVFs, given appropriate arterial feeder access. Advances during the later years with regard to technical equipment and liquid embolic materials now allow far distal arterial catheter positioning when injecting better controllable embolic agents. This has increased both the proportion of dAVFs being accessible to primary transarterial EVT and the frequency of complete dAVF closures by endovascular means.

Stereotactic radiosurgery (SRS) can be an alternative/ adjuvant to elective EVT/surgery of cranial dAVFs, especially of type 1 [9]. This treatment is gentle to the patient, carries low complication risk, and offers favorable obliteration rates over time. It can hence be a treatment of choice in elderly/frail patients. The disadvantage is delayed dAVF obliteration, with a typical latency period of 1-3 years.

Due to the high frequency of early rebleeds among our 20 acute hemorrhagic patients, we recommend that the swiftness of treatment in a hemorrhaging dAVF should be similar to that of aneurysmal subarachnoid hemorrhage. This is independent of whether the symptom at ictus/cause of bleed is acute headache/dAVF venous aneurysm or acute neurological symptoms without headache/bleed from a small parenchymal vein, as we have experienced that both types rebleed early. The longer time span from arrival to primary EVT, together with the lower occlusion success (59\%) in 
EVT, have further made us change our management principles of patients presenting with acute hemorrhage from dAVF; surgery is now our treatment of choice unless directly contraindicated. This contrasts Baltsavias et al. who use primary surgery only in cases of emergency hematoma evacuation [5].

\section{dAVF characteristics and clinical symptoms}

Others have previously described the relationships between dAVF characteristics (lesion location and venous drainage) and neurological symptoms, ocular symptoms, intracranial hemorrhage, and pulsatile tinnitus $[3,4,12,22,23,25,28$, 29]. When dAVFs recruit cerebral/orbital veins for drainage, increased pressure develops in those compartments and may cause cerebral venous ischemia/neurological symptoms and ocular symptoms. A decompensation of the cerebral venous system may further result in intracranial hemorrhage. In contrast, pulsatile tinnitus is not connected to an increase in pressure but rather to the anatomical intimacy of the dAVF flow to the middle ear. About $85 \%$ of our patients that presented with pulsatile tinnitus had dAVFs located in close approximation to the middle ear and the tinnitus persisted when there was residual flow but resolved upon complete dAVF obliteration. Likewise, all our 14 patients who presented with ocular symptoms had dAVF orbital venous drainage. Their symptoms resolved upon complete dAVF closure but persisted if there was some residual dAVF flow. Furthermore, our 12 patients that presented with neurological symptoms or hemorrhage had dAVFs with leptomeningeal venous drainage except for one patient presenting with a partial CN XII deficit. Some residual neurological symptoms in spite of complete dAVF occlusion could possibly indicate a situation of a certain non-reversible neurological damage at the point of time when the dAVFs were treated. The relationship between dAVF and headache seems to be less direct as $43 \%$ of our headache patients had residual headache in spite of complete dAVF obliteration.

\section{Procedural complications}

Our frequency of treatment complications was higher than that observed in several other studies $[2,18,19,21,22,29$, 32, 33], comparable to those of Piippo et al. [26] and Gross and $\mathrm{Du}$ [16] but lower than that of Kakarla et al. [20].

There were certain common features among our EVT patients that suffered permanent $\mathrm{CN}$ deficits: they all underwent transarterial embolization with the low molecular liquid embolic agent Onyx ${ }^{\circledR}$. All of them were further treated early in the series (November 2012-January 2013) with the available technical equipment at that time and prior to start in our use of the newer generation of liquid embolic agents (Squid® (2014) and PHIL® (2015). Upon closing the dural arterial supply to a region with Onyx ${ }^{\circledR}$, compounds of this agent may migrate into the vasa nervorum of cranial nerve(s) and cause $\mathrm{CN}$ ischemia [14]. If so, one could anticipate the $\mathrm{CN}$ deficit to be present early after treatment, which presently was the case. For opacity, Onyx is mixed with tantalum power. However, the rapidly decreasing opacity, as a result of the tantalum powder, may compromise visual control during EVT, which is much more prominent with Onyx than Squid [24]. Lack of full visualization might thus have been contributing to the $\mathrm{CN} \mathrm{X}$ and XII complications; however, the cause of the CN VI deficit remains unclear. We have had no $\mathrm{CN}$ deficits as complication to endovascular dAVF treatment after January 2013.

There were also certain common features in the patients that suffered permanent $\mathrm{CN}$ deficit after surgery: both underwent extensive drilling of the petrous bone for sinus exposure/due to massive bleeding and both had the dAVF excised together with resection of a sinus that was located close to the cranial nerve of interest. One may speculate on whether it was the heat produced by the extensive drilling or the coagulation/ cutting of dura close to the cranial nerve that led to the deficit. In retrospect, we could have treated both surgical cases differently. The patient with an acute hemorrhaging type IV dAVF that had already undergone unsuccessful primary EVT could have been managed by just clipping of the dAVF draining vein. The other patient suffering from headache and pulsatile tinnitus from a monstrous type II dAVF located along the sigmoid sinus that had already undergone three arterial treatment procedures could have been managed through transvenous endovascular closure of the fistula/sigmoid sinus.

\section{Limitations}

The retrospective nature of this single-center report and the moderate number of patients are limitations of the study. On the other hand, a strength is that we had a low threshold for switching treatment modality when we did not obtain angiographic dAVF obliteration after the first treatment procedure. This reflects our goal of obtaining total obliteration quickly in dAVFs with leptomeningeal venous drainage.

Since our hospital is the national referral center for EVT in neurovascular malformations, there may be a referral bias of dAVF cases deemed suitable for EVT, whereas surgical cases may have been handled locally. If present, this number would be very low, so that the present study includes the vast majority of patients treated for cranial dAVFs in Norway and therefore should adequately reflect features of this disease and treatment outcome. 


\section{Conclusions}

From our experience, we recommend EVT as first treatment modality in types I, II, and in non-hemorrhagic type III/IV dAVFs. In contrast, we recommend surgery as first treatment choice in acute hemorrhagic dAVFs, and as secondary choice in type III/IV dAVFs not successfully occluded by EVT. Combining the two modalities, angiographic obliteration can be anticipated in $9 / 10$ patients with dAVF, including all type III/IV dAVFs, at a low treatment risk. Except for headache, relief of non-hemorrhagic symptoms seems to be closely linked to obliteration of the dAVFs.

Funding Open access funding provided by University of Oslo (incl Oslo University Hospital).

\section{Declarations}

Ethics approval The study was approved as a quality project by the institution data protection officer (number 2012/14909). All procedures performed in studies involving human participants were in accordance with the ethical standards of the institutional and/or national research committee and with the 1964 Helsinki declaration and its later amendments or comparable ethical standards.

Consent to participate Informed consent was not required for this study.

Conflict of interest The authors declare no competing interests.

Open Access This article is licensed under a Creative Commons Attribution 4.0 International License, which permits use, sharing, adaptation, distribution and reproduction in any medium or format, as long as you give appropriate credit to the original author(s) and the source, provide a link to the Creative Commons licence, and indicate if changes were made. The images or other third party material in this article are included in the article's Creative Commons licence, unless indicated otherwise in a credit line to the material. If material is not included in the article's Creative Commons licence and your intended use is not permitted by statutory regulation or exceeds the permitted use, you will need to obtain permission directly from the copyright holder. To view a copy of this licence, visit http://creativecommons.org/licenses/by/4.0/.

\section{References}

1. Al-Shahi R, Bhattacharya JJ, Currie DG, Papanastassiou V, Ritchie V, Roberts RC, Sellar RJ, Warlow CP (2003) Prospective, population-based detection of intracranial vascular malformations in adults: the Scottish Intracranial Vascular Malformation Study (SIVMS). Stroke 34:1163-1169

2. Baltsavias G, Valavanis A (2014) Endovascular treatment of 170 consecutive cranial dural arteriovenous fistulae: results and complications. Neurosurg Rev 37:63-71

3. Baltsavias G, Roth P, Valavanis A (2015) Cranial dural arteriovenous shunts. Part 3. Classification based on the leptomeningeal venous drainage. Neurosurg. Rev. 38:273-281; discussion 281

4. Baltsavias G, Spiessberger A, Hothorn T, Valavanis A (2015) Cranial dural arteriovenous shunts. Part 4. Clinical presentation of the shunts with leptomeningeal venous drainage. Neurosurg. Rev. 38:283-291; discussion 291

5. Baltsavias G, Valavanis A, Regli L (2019) Cranial dural arteriovenous shunts: selection of the ideal lesion for surgical occlusion according to the classification system. Acta Neurochir (Wien) 161:1775-1781

6. Barrow DL, Spector RH, Braun IF, Landman JA, Tindall SC, Tindall GT (1985) Classification and treatment of spontaneous carotid-cavernous sinus fistulas. J Neurosurg 62:248-256

7. Borden JA, Wu JK, Shucart WA (1995) A proposed classification for spinal and cranial dural arteriovenous fistulous malformations and implications for treatment. J Neurosurg 82:166-179

8. Brown RD Jr, Wiebers DO, Nichols DA (1994) Intracranial dural arteriovenous fistulae: angiographic predictors of intracranial hemorrhage and clinical outcome in nonsurgical patients. J Neurosurg 81:531-538

9. Chen CJ, Lee CC, Ding D, Starke RM, Chivukula S, Yen CP, Moosa S, Xu Z, Pan DH, Sheehan JP (2015) Stereotactic radiosurgery for intracranial dural arteriovenous fistulas: a systematic review. J Neurosurg 122:353-362

10. Cognard C, Gobin YP, Pierot L, Bailly AL, Houdart E, Casasco A, Chiras J, Merland JJ (1995) Cerebral dural arteriovenous fistulas: clinical and angiographic correlation with a revised classification of venous drainage. Radiology 194:671-680

11. Collice M, D’Aliberti G, Talamonti G, Branca V, Boccardi E, Scialfa G, Versari PP (1996) Surgical interruption of leptomeningeal drainage as treatment for intracranial dural arteriovenous fistulas without dural sinus drainage. J Neurosurg 84:810-817

12. Davies MA, TerBrugge K, Willinsky R, Coyne T, Saleh J, Wallace MC (1996) The validity of classification for the clinical presentation of intracranial dural arteriovenous fistulas. J Neurosurg 85:830-837

13. Djindjian R, Merland, J.-J., Theron, J. (1977) Super-selective arteriography of the external carotid artery. Springer-Verlag New York

14. Gaynor BG, Elhammady MS, Jethanamest D, Angeli SI, Aziz-Sultan MA (2014) Incidence of cranial nerve palsy after preoperative embolization of glomus jugulare tumors using Onyx. J Neurosurg 120:377-381

15. Grisoli F, Vincentelli F, Fuchs S, Baldini M, Raybaud C, Leclercq TA, Vigouroux RP (1984) Surgical treatment of tentorial arteriovenous malformations draining into the subarachnoid space. Report of four cases J Neurosurg 60:1059-1066

16. Gross BA, Du R (2012) The natural history of cerebral dural arteriovenous fistulae. Neurosurgery 71:594-602; discussion 602-593

17. Gross BA, Albuquerque FC, Moon K, McDougall CG (2017) Evolution of treatment and a detailed analysis of occlusion, recurrence, and clinical outcomes in an endovascular library of 260 dural arteriovenous fistulas. J Neurosurg 126:1884-1893

18. Gross BA, Albuquerque FC, McDougall CG, Jankowitz BT, Jadhav AP, Jovin TG, Du R (2018) A multi-institutional analysis of the untreated course of cerebral dural arteriovenous fistulas. J Neurosurg 129:1114-1119

19. Guedin P, Gaillard S, Boulin A, Condette-Auliac S, Bourdain F, Guieu S, Dupuy M, Rodesch G (2010) Therapeutic management of intracranial dural arteriovenous shunts with leptomeningeal venous drainage: report of 53 consecutive patients with emphasis on transarterial embolization with acrylic glue. J Neurosurg 112:603-610

20. Kakarla UK, Deshmukh VR, Zabramski JM, Albuquerque FC, McDougall CG, Spetzler RF (2007) Surgical treatment of highrisk intracranial dural arteriovenous fistulae: clinical outcomes and avoidance of complications. Neurosurgery 61:447-457; discussion 457-449

21. Kim DJ, Willinsky RA, Krings T, Agid R, Terbrugge K (2011) Intracranial dural arteriovenous shunts: transarterial glue 
embolization-experience in 115 consecutive patients. Radiology 258:554-561

22. Kirsch M, Liebig T, Kühne D, Henkes H (2009) Endovascular management of dural arteriovenous fistulas of the transverse and sigmoid sinus in 150 patients. Neuroradiology 51:477-483

23. Lasjaunias $\mathrm{P}$, Chiu M, ter Brugge $\mathrm{K}$, Tolia A, Hurth M, Bernstein M (1986) Neurological manifestations of intracranial dural arteriovenous malformations. J Neurosurg 64:724-730

24. Mason JR, Dodge C, Benndorf G (2018) Quantification of tantalum sedimentation rates in liquid embolic agents. Interv Neuroradiol 24:574-579

25. Oh JT, Chung SY, Lanzino G, Park KS, Kim SM, Park MS, Kim HK (2012) Intracranial dural arteriovenous fistulas: clinical characteristics and management based on location and hemodynamics. J Cerebrovasc Endovasc Neurosurg 14:192-202

26. Piippo A, Niemelä M, van Popta J, Kangasniemi M, Rinne J, Jääskeläinen JE, Hernesniemi J (2013) Characteristics and longterm outcome of 251 patients with dural arteriovenous fistulas in a defined population. J Neurosurg 118:923-934

27. Reynolds MR, Lanzino G, Zipfel GJ (2017) Intracranial Dural Arteriovenous Fistulae. Stroke 48:1424-1431

28. Shin NY, Kwon YS, Ha SY, Kim BM, Kim DI, Kim DJ (2013) Venous angioarchitectural features of intracranial dural arteriovenous shunt and its relation to the clinical course. Neuroradiology 55:1119-1127

29. Signorelli F, Della Pepa GM, Sabatino G, Marchese E, Maira G, Puca A, Albanese A (2015) Diagnosis and management of dural arteriovenous fistulas: a 10 years single-center experience. Clin Neurol Neurosurg 128:123-129

30. Soderman M, Pavic L, Edner G, Holmin S, Andersson T (2008) Natural history of dural arteriovenous shunts. Stroke 39:1735-1739

31. Sorteberg W, Sorteberg A, Jacobsen EA, Rønning P, Eide PK (2020) Intracranial hemorrhage from dural arteriovenous fistulas: symptoms, early rebleed, and acute management: a single-center 8-year experience. Neurosurgery Open 1:1-10

32. Strom RG, Botros JA, Refai D, Moran CJ, Cross DT, 3rd, Chicoine MR, Grubb RL, Jr., Rich KM, Dacey RG, Jr., Derdeyn CP, Zipfel GJ (2009) Cranial dural arteriovenous fistulae: asymptomatic cortical venous drainage portends less aggressive clinical course. Neurosurgery 64:241-247; discussion 247-248

33. van Dijk JM, TerBrugge KG, Willinsky RA, Wallace MC (2004) Selective disconnection of cortical venous reflux as treatment for cranial dural arteriovenous fistulas. J Neurosurg 101:31-35

34. Zipfel GJ, Shah MN, Refai D, Dacey RG Jr, Derdeyn CP (2009) Cranial dural arteriovenous fistulas: modification of angiographic classification scales based on new natural history data. Neurosurg Focus 26:E14

Publisher's note Springer Nature remains neutral with regard to jurisdictional claims in published maps and institutional affiliations. 